\title{
Twenty-four-hour esophageal pH monitoring in children and adolescents with chronic and/or recurrent rhinosinusitis
}

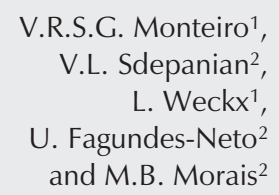

\author{
Disciplinas de ${ }^{1}$ Otorrinolaringologia Pediátrica, and \\ ${ }^{2}$ Gastroenterologia Pediátrica, Escola Paulista de Medicina, \\ Universidade Federal de São Paulo, São Paulo, SP, Brasil
}

\section{Correspondence \\ V.L. Sdepanian \\ Rua dos Otonis, 880, Apto. 102 \\ 04025-002 São Paulo, SP \\ Brasil \\ Fax: +55-11-5539-0001 \\ E-mail: sdepanian@nw.com.br}

Publication supported by FAPESP

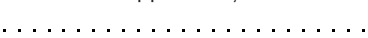

Received April 22, 2004

Accepted October 19, 2004

\begin{abstract}
Gastroesophageal reflux (GER) disorder was studied in children and adolescents with chronic and/or recurrent rhinosinusitis not associated with bronchial asthma. Ten children with a clinical and radiological diagnosis of chronic and/or recurrent rhinosinusitis, consecutively attended at the Pediatric Otolaryngology Outpatient Clinic, Federal University of São Paulo, were evaluated. Prolonged esophageal pH monitoring was used to investigate GER disorder. The mean age of the ten patients evaluated (eight males) was $7.4 \pm 2.4$ years. Two patients presented vomiting as a clinical manifestation and one patient presented retrosternal pain with a burning sensation. Twenty-four-hour esophageal $\mathrm{pH}$ monitoring was performed using the Sandhill apparatus. An antimony probe electrode was placed in the lower third of the esophagus, confirmed by fluoroscopy and later by a chest X-ray. The parameters analyzed by esophageal $\mathrm{pH}$ monitoring included: total percent time of the presence of acid esophageal $\mathrm{pH}$, i.e., $\mathrm{pH}$ below 4 $(<4.2 \%)$; total number of acid episodes ( $<50$ episodes); number of reflux episodes longer than 5 min ( 3 or less), and duration of the longest reflux episode ( $<9.2 \mathrm{~min})$. One patient $(1 / 10,10 \%)$ presented a 24-h esophageal $\mathrm{pH}$ profile compatible with GER disorder. This data suggest that an association between chronic rhinosinusitis not associated with bronchial asthma and GER disorder may exist in children and adolescents, especially in those with compatible GER disorder symptoms. In these cases, 24-h esophageal $\mathrm{pH}$ monitoring should be performed before indicating surgery, since the present data suggest that $10 \%$ of chronic rhinosinusitis surgeries can be eliminated.
\end{abstract}

Key words

- Sinusitis

- Chronic disease

- Gastroesophageal reflux

- Children

- Adolescents

- Esophageal pH monitoring

\section{Introduction}

Gastroesophageal reflux (GER) consists of spontaneous return of gastric content to the esophagus (1). This phenomenon is gen- erally considered to be physiological despite the existence of an antiflux barrier system, which includes the Hiss angle, gastric rosette, crural diaphragm, phrenic-esophageal ligament, and lower esophageal sphincter (2). 
Physiological GER should be differentiated from gastroesophageal reflux disease (GERD), which is characterized by signs and/or symptoms secondary to GER, affecting life quality and leading to esophageal tissue lesions. The main manifestations of GERD are growth deficit, infant apnea, esophagitis, bronchial asthma, aspirative pneumonia, and anemia (3). Otorhinolaryngological manifestations have also been described, such as laryngospasm, chronic cough, laryngeal stridor, laryngitis, subglottic stenosis, laryngeal granulomas, vocal chord nodules, persistent otitis media, rhinopharyngitis, choanal stenosis, adenoidal hypertrophy, nasal drainage, and chronic sinusitis (4-7). It is important to point out that respiratory and otorhinolaryngological manifestations of GERD may occur in patients without typical symptoms of the disease, i.e., regurgitation, vomiting and/or retrosternal pain with a burning sensation (5).

The etiology of the inflammatory process in the mucosa of the upper airways and the mechanisms that determine and/or maintain this process have not been elucidated (8). When acid refluxes from the stomach and makes contact with the upper respiratory mucosa, it causes irritation and edema which impair the mucociliary clearance function $(5,9,10)$. Another possible mechanism is hyper-reactivity of the autonomous nervous system caused by reflux, with consequent edema and obstruction, similar to that observed in vasomotor rhinitis (10). The edematous nasopharynx and/or facial sinus mucosa may cause ostium sinusal obstruction followed by the development of sinusitis $(5,9,10)$.

Today, prolonged monitoring of esophageal $\mathrm{pH}$ is the best available method for GERD diagnosis. It not only allows the detection of reflux, but also provides the frequency and duration of acid reflux episodes, $\mathrm{pH}<4$, and the analysis of its relationship to meals, position and concomitance with possible symptoms attributed to GERD (1).
There is some doubt concerning the real importance of the association between otorhinolaryngological manifestations in children and GERD, with few reports on this topic. The majority of the studies refer to laryngeal disorders, mainly in adults $(4,8)$, with few references to nasosinusal disorders in children and adolescents, especially in those without bronchial asthma $(5,6,9,11)$.

The purpose of the present study was to investigate GERD in children and adolescents with chronic and/or recurrent rhinosinusitis not associated with bronchial asthma using 24-h esophageal pH monitoring.

\section{Patients and Methods}

Thirteen children were evaluated consecutively at the Pediatric Otolaryngology Outpatient Clinic of the Federal University of São Paulo, Escola Paulista de Medicina (UNIFESP/EPM), with a clinical and radiological diagnosis of chronic and/or recurrent rhinosinusitis.

Clinical diagnosis was based on the criteria of the International Conference of Facial Sinus Disorders (11), as follows: persistence of signs and/or symptoms for at least 12 weeks or six episodes of acute sinusitis a year, with a minimal interval between episodes of at least 10 days after the end of treatment. The major signs and symptoms are nasal obstruction, rhinorrhea, headache during the crisis, pressure pain in the face, and olfactory disorder. Fever, halitosis, cough, and irritability are considered to be minor symptoms.

The following inclusion criteria were utilized during the acute phase: rhinorrhea and diurnal and nocturnal cough in association with the otorhinolaryngological exam. Anterior rhinoscopy examination revealed hyperemia of anterior nasal conchae, edema with mucous-purulent secretion in the nasal cavity draining mainly through the middle meatus, and/or oroscopy revealed mucous-purulent secretion draining from rhinopharynx 
through the posterior wall of the pharynx and/or a hyperemic pharynx with granules. Exclusion criteria were: neoplasias, immunodeficiency, nasosinusal polyposis, and respiratory symptom complex due to bronchial asthma and repetitive bronchopneumonia. Three patients with chronic and/or recurrent rhinosinusitis were excluded from the initial sample due to the presence of the following disorders: transient hypogammaglobulinemia, polysaccharide acid deficiency with normal serum immunoglobulin, and glucose 6-phosphate-dehydrogenase deficiency.

Radiological findings were obtained by simple X-rays of the facial sinuses as follows: frontal-nasal-plate and menton-nasalplate. Whenever possible, the diagnosis was confirmed by computed tomography of the facial sinuses.

Twenty-four-hour esophageal $\mathrm{pH}$ monitoring was performed using the Sandhill apparatus. An antimony probe electrode was placed in the lower third of the esophagus and its position was confirmed by fluoroscopy and later by a chest X-ray. The probe was placed in such a way that the tip of the electrode would lie over the third vertebral body above the diaphragm throughout the respiratory cycle (12). For the exam, patients were admitted to the Pediatric Unit of São Paulo Hospital, Federal University of São Paulo, Escola Paulista de Medicina. Mealtime, changes in decubitus, the occurrence of vomiting, and any other clinical manifestations were recorded. It is important to emphasize that no physical activity or nutritional restraints were imposed on the children during hospitalization, with no changes in their daily routine. No clinical occurrence was observed during the exams.

The parameters analyzed by esophageal $\mathrm{pH}$ monitoring, as well as their respective normal values according to Johnson and DeMeester $(13,14)$, presented in parentheses, included: total percent time of the presence of acid esophageal $\mathrm{pH}$, i.e., $\mathrm{pH}$ below 4 $(<4.2 \%)$; total number of acid episodes $(<50$ episodes); number of reflux episodes longer than 5 min (3 or less), and duration of the longest reflux episode ( $<9.2 \mathrm{~min}$ ).

The Ethics Committee of the Federal University of São Paulo, Escola Paulista de Medicina, approved the study and written informed consent was obtained from the persons responsible for the patients.

\section{Results}

Of the 10 children studied, 8 were males and 2 females, ranging in age from 5 to 12 years old, with a mean age of $7.4 \pm 2.4$ years old.

Table 1 shows the distribution of the patients according to age, gastrointestinal symptomatology and facial sinus radiological and computed tomography findings. Patient \#7 presented pain in the retrosternal region with a burning sensation, and patient \#8 had undergone previous surgery for GER correction at 2 years and 3 months of age.

The results of 24-h esophageal $\mathrm{pH}$ monitoring (Table 2) showed that patient \#7 (1/ $10,10 \%)$ presented percent of time with acid esophageal $\mathrm{pH}(<4)$ above $4.2 \%$ and $24-\mathrm{h}$ numerical $\mathrm{pH}$ score of all results of the test equal to 18.8 , which is considered pathological according to the criterion of Johnson and DeMeester (13).

\section{Discussion}

Chronic and/or recurrent sinusitis in children results from the interaction of multiple factors, such as recurrent upper airway infections, allergy, GERD, exposure to irritant agents such as smoking and swimming, cystic fibrosis, primary or secondary immunodeficiency, mucociliary disorders, and anatomical abnormalities of the nose and nasal sinus (7).

There are few studies correlating chronic rhinosinusitis with GERD. Barbero (5) identified GERD using 24-h esophageal $\mathrm{pH}$ monitoring in 7 children with chronic sinusitis 
Table 1. Distribution of patients according to age, gastrointestinal symptoms, radiological diagnosis, and facial sinus computed tomography.

\begin{tabular}{|c|c|c|c|c|c|}
\hline \multirow[t]{2}{*}{ Patient } & \multirow[t]{2}{*}{$\begin{array}{l}\text { Age } \\
\text { (years) }\end{array}$} & \multicolumn{2}{|c|}{$\begin{array}{l}\text { Gastrointestinal symptoms } \\
\text { at the time of the study }\end{array}$} & \multicolumn{2}{|c|}{ Diagnosis of rhinosinusitis } \\
\hline & & Vomiting & $\begin{array}{l}\text { Retrosternal pain } \\
\text { with burning } \\
\text { sensation }\end{array}$ & Facial sinus X-ray & $\begin{array}{c}\text { Facial sinus computed } \\
\text { tomography }\end{array}$ \\
\hline 1 & 8 & No & No & $\begin{array}{l}\text { Bilateral maxillary sinus thickening } \\
(++++)\end{array}$ & Not performed \\
\hline 2 & 6 & No & No & $\begin{array}{l}\text { Bilateral ethmoidal opacification } \\
\text { with maxillary sinus thickening }(+++)\end{array}$ & Not performed \\
\hline 3 & 6 & No & No & $\begin{array}{l}\text { Bilateral ethmoidal and maxillary } \\
\text { sinus opacification }\end{array}$ & Not performed \\
\hline 4 & 11 & No & No & Bilateral maxillary sinus opacification & Not performed \\
\hline 5 & 5 & No & No & $\begin{array}{l}\text { Bilateral maxillary and ethmoidal } \\
\text { sinus opacification }\end{array}$ & $\begin{array}{l}\text { Maxillary and ethmoidal } \\
\text { sinus thickening }(++++)\end{array}$ \\
\hline 6 & 8 & No & No & $\begin{array}{l}\text { Bilateral maxillary and ethmoidal } \\
\text { sinus opacification }\end{array}$ & $\begin{array}{l}\text { Ethmoidal opacification, } \\
\text { left maxillary and } \\
\text { sphenoidal sinus } \\
\text { thickening }(+++)\end{array}$ \\
\hline 7 & 12 & Yes & Often & $\begin{array}{l}\text { Bilateral maxillary and ethmoidal } \\
\text { sinus opacification }\end{array}$ & Not performed \\
\hline 8 & 6 & Yes & No & $\begin{array}{l}\text { Right maxillary opacification and } \\
\text { left maxillary thickening }(+++)\end{array}$ & $\begin{array}{l}\text { Maxillary sinus } \\
\text { thickening }(+++)\end{array}$ \\
\hline 9 & 8 & No & No & $\begin{array}{l}\text { Bilateral maxillary and ethmoidal } \\
\text { opacification }\end{array}$ & $\begin{array}{l}\text { Ethmoidal and maxillary } \\
\text { sinus thickening }(+++)\end{array}$ \\
\hline 10 & 5 & No & No & Bilateral maxillary opacification & $\begin{array}{l}\text { Bilateral ethmoidal opa- } \\
\text { cification with maxillary } \\
\text { sinus thickening }(+++)\end{array}$ \\
\hline
\end{tabular}

Table 2. Results of 24-h esophageal pH monitoring of 10 children and adolescents with chronic and/or recurrent rhinosinusitis.

\begin{tabular}{cccccc}
\hline Patient & $\begin{array}{c}\text { Time of acid } \\
\text { esophageal } \\
\text { pH < }(\%)\end{array}$ & $\begin{array}{c}\text { Total number of } \\
\text { acid episodes } \\
\text { (\%) }\end{array}$ & $\begin{array}{c}\text { Number of episodes } \\
\text { longer than } \\
5 \text { min }\end{array}$ & $\begin{array}{c}\text { Duration of the } \\
\text { longest episode } \\
\text { (min) }\end{array}$ & $\begin{array}{r}\text { Score according } \\
\text { to Johnson and } \\
\text { DeMeester (13) }\end{array}$ \\
\hline 1 & 0.19 & 8 & 0 & 1.0 & 1.45 \\
2 & 0.00 & 0 & 0 & 0.0 & 0.33 \\
3 & 1.00 & 28 & 0 & 1.0 & 3.40 \\
4 & 0.16 & 7 & 0 & 0.5 & 1.24 \\
5 & 3.19 & 12 & 1 & 7.0 & 12.56 \\
6 & 0.86 & 15 & 0 & 4.2 & 4.45 \\
7 & 4.62 & 37 & 0 & 7.9 & 18.80 \\
8 & 2.04 & 21 & 0 & 2.9 & 5.37 \\
9 & 0.00 & 2 & 0 & 0.0 & 1.90 \\
10 & 0.01 & & 0.1 & 0.57 \\
\hline
\end{tabular}

Patient \#7 is the positive patient. 
who did not respond favorably to surgical treatment of the sinusopathy. These patients recovered from their otolaryngological symptoms after the institution of treatment for GERD. With this background, 22 children with chronic sinusitis and indication for sinusopathy surgery were assigned to 24-h esophageal $\mathrm{pH}$ monitoring and abnormal results were observed in $16(72.7 \%)$ of them (5). One third of the patients presented recurrent chronic abdominal pain, flatulence, hiccups, and thoracic pain. After the institution of anti-reflux therapy, total remission of the symptoms was observed in 10 patients and partial improvement in 3 patients. Barbero (5) concluded that there is an association between rhinosinusitis and GERD in children and that GERD should be considered before surgical treatment for sinusitis is indicated. Bothwell et al. (15) observed an important reduction in the number of children suffering from chronic sinusitis who required surgical treatment for sinusopathy after GERD treatment (11). Halstead (6) reported that $6(55 \%)$ of 11 patients with chronic rhinosinusitis and otitis had a favorable response to the anti-reflux medication, and 5 of these patients (45\%) presented abnormal results of 24-h esophageal $\mathrm{pH}$ monitoring. Phipps et al. (9), studying 30 children with chronic sinusitis, found the presence of pathological reflux in the distal esophagus in $19(63 \%)$ of them. Fifteen (79\%) of these 19 patients showed a favorable response to the clinical treatment of GERD.

In the present study, GERD was identified in $1(10 \%)$ of the 10 patients with chronic rhinosinusitis, therefore, in a smaller proportion of patients than reported in previous studies $(5,6,9,11)$. It should be mentioned that a well-established diagnosis of chronic and/or recurrent rhinosinusitis in children is not very frequent, especially when children with bronchial asthma are excluded from the samples studied. One of the exclusion criteria used in the present study was the presence of a respiratory symptom complex, which could be one of the characteristics explaining the lower frequency of altered $\mathrm{pH}$ monitoring in our patients, since this exclusion criterion was not adopted in the literature. Regarding the symptoms related to GERD, the only patient with altered $\mathrm{pH}$ monitoring presented vomiting and a retrosternal burning sensation. Only another patient with normal esophageal $\mathrm{pH}$ monitoring reported a symptom related to GERD, i.e., repetitive vomiting.

Some issues should be discussed regarding esophageal $\mathrm{pH}$ monitoring. First, regarding to the location of the electrode, the European Society for Pediatric Gastroenterology and Nutrition Working Group on GER recommended the use of fluoroscopy for electrode placement (12). The tip of the electrode should be positioned over the third vertebral body above the diaphragm (16). The second issue is where the probe electrode should be placed for evaluation of GERD and otorhinolaryngological disorders: in the distal esophagus only, in the distal and proximal esophagus, or in the distal esophagus and pharynx (9,17-20). Phipps et al. (9), using two electrodes placed in the distal esophagus and nasopharynx, concluded that the use of a single electrode placed in the distal esophagus is sufficient to indicate GERD treatment. Little et al. (20) could not define at what point the frequency and/or duration of pharyngeal reflux becomes pathologic. A recent editorial in the Journal of Pediatric Gastroenterology and Nutrition alerted that caution must be exercised in the interpretation of results of pharyngeal $\mathrm{pH}$ monitoring (21). There is also another difficulty related to the correct placement of double electrodes using a single catheter because the length of the esophagus varies according to age and height. Maldonado et al. (22) improved a triple-electrode bifurcated adjustable $\mathrm{pH}$ probe to identify true hypopharyngeal acid reflux episodes in adults.

Considering the difficulties in the correct 
placement of each double probe using a single catheter, and the lack of data about pharyngeal reflux in pediatric patients, we performed the present study using a distal esophageal $\mathrm{pH}$ probe.

The results of the present investigation suggest that there may be an association between chronic rhinosinusitis and GERD in children and adolescents, especially those presenting typical GERD symptoms. In these cases, 24-h esophageal $\mathrm{pH}$ monitoring should be suggested before surgery is indicated. However, further studies involving larger samples are necessary to confirm the real dimension of the association between GERD and chronic and/or recurrent rhinosinusitis.

\section{References}

1. Hillemeier AC (2000). Gastroesophageal reflux. In: Walker WA, Durie PR \& Hamilton JR (Editors), Pediatric Gastrointestinal Disease. 3rd edn. Mosby-Year Book, Inc., St. Louis, MO, USA, 289319 .

2. Orenstein SR (1994). Gastroesophageal reflux. In: Hyman PE (Editor), Pediatric Gastrointestinal Motility Disorders. 1st edn. Academy Professional Information Services, Inc., New York, 55-88.

3. Orenstein SR, Izadnia F \& Khan S (1999). Gastroesophageal disease in children. Gastroenterology Clinics of North America, 28: 947-969.

4. Koufman JA (1991). The otorhinolaryngologic manifestation of gastroesophageal reflux disease (GRD). A clinical investigation of 225 patients using ambulatory 24-hour $\mathrm{pH}$ monitoring and experimental investigation of the role of acid and pepsin in the development of laryngeal injury. Laringoscope, 101 (Suppl 53): 1-73.

5. Barbero GJ (1996). Gastroesophageal reflux and upper airway disease. Otolaryngologic Clinics of North America, 29: 27-38.

6. Halstead LA (1999). Role of gastroesophageal reflux in pediatric upper airway disorders. Otolaryngology - Head and Neck Surgery, 120: 208-214.

7. Parsons DS (1996). Chronic sinusitis: a medical or surgical disease? Otolaryngology Clinics of North America, 29: 1-9.

8. Contencin P \& Narcy P (1991). Nasopharyngeal pH monitoring in infants and children with chronic rhinopharyngitis. International Journal of Pediatric Otorhinolaryngology, 22: 249-256.

9. Phipps CD, Wood WE, Gibson WS \& Cochran WJ (2000). Gastroesophageal reflux contributing to chronic sinus disease in children. Archives of Otolaryngology - Head and Neck Surgery, 126: 831-836.

10. Jailwala JA \& Shaker R (2000). Oral and pharyngeal complications of gastroesophageal reflux disease. Journal of Clinical Gastroenterology, 30 (Suppl): S35-S38.

11. Lund VJ \& Kennedy DW (1995). Quantification for staging sinusitis. The staging and therapy group. Annals of Otology, Rhinology, and Laryngology, 167 (Suppl): 17-21.

12. Vandenplas $Y$, Belli D, Boige $N$ et al. (1992). A standardized protocol for the methodology of esophageal $\mathrm{pH}$ monitoring and interpretation of the data for the diagnosis of gastroesophageal reflux. (ESPGHAN - society statement). Journal of Pediatric Gastroenterol- ogy and Nutrition, 14: 467-471.

13. Johnson LF \& DeMeester TR (1974). Twenty-four-hour pH monitoring of the distal esophagus. A quantitative measure of gastroesophageal reflux. American Journal of Gastroenterology, 62: 325-332.

14. DeMeester TR, Wang $\mathrm{Cl}$, Wernly JA, Pellegrini CA, Little AG, Klementschitsch P, Bermudez G, Johnson LF \& Skinner DB (1980). Technique, indications, and clinical use of 24 hour esophageal $\mathrm{pH}$ monitoring. Journal of Thoracic and Cardiovascular Surgery, 79: 656-670.

15. Bothwell MR, Parsons DS, Talbot A, Barbero GJ \& Wilder B (1999). Outcome of reflux therapy on pediatric chronic sinusitis. Otolaryngology - Head and Neck Surgery, 121: 255-262.

16. Vandenplas $Y$ (1994). Esophageal pH monitoring. In: Hyman PE (Editor), Pediatric Gastrointestinal Motility Disorders. 1st edn. Academy Professional Information Services, Inc., New York, 253-263.

17. Bagucka B, Badriul H, Vandemaele $K$, Troch E \& Vandenplas $Y$ (2000). Normal ranges of continuous $\mathrm{pH}$ monitoring in the proximal esophagus. Journal of Pediatric Gastroenterology and Nutrition, 31: 244-247.

18. Gustafsson PM \& Tibbling L (1988). 24-hour oesophageal two-level $\mathrm{pH}$ monitoring in healthy children and adolescents. Scandinavian Journal of Gastroenterology, 23: 91-94.

19. Johansson KE, Boeryd B, Fransson SG \& Tibbling L (1986). Oesophageal reflux tests, manometry, endoscopy, biopsy, and radiology in healthy subjects. Scandinavian Journal of Gastroenterology, 21: 399-406.

20. Little JP, Matthews BL, Glock MS, Koufman JA, Reboussin DM, Loughlin CJ \& McGuirt WF (1997). Extraesophageal pediatric reflux: 24-hour double-probe pH monitoring in 222 children. Annals of Otology, Rhinology, and Laryngology, 106 (Suppl): 1-16.

21. Vasundhara T (2002). Gastroesophageal reflux and supraesophageal complications: really true or ballyhoo? Journal of Pediatric Gastroenterology and Nutrition, 34: 269-273.

22. Maldonado A, Diederich L, Castell DO, Gideon RM \& Katz PO (2003). Laryngopharyngeal reflux identified using a new catheter design: defining normal values and excluding artifacts. Laryngoscope, 113: 349-355 